\title{
A CONSTRUÇÃO DE AMBIENTES SAUDÁVEIS NA ESCOLA: INOVAÇÕES NA PARTICIPAÇÃO DE CRIANÇAS
}

\author{
Olga Maria Ramalho de Albuquerque, Cleber da Silva Alves
}

Universidade de Brasília
Brasília, Distrito Federal
E-mail: olgamaria@unb.br, alves-cleber@hotmail.com

\section{Helena Maria Campos, Alberto Mesaque Martins}

Centro de Pesquisa René Rachou/Fiocruz

Belo Horizonte, Minas Gerais

E-mail: helenacampos@cpqrr.fiocruz.br, mesaque@ cpqrr.fiocruz.br

\section{Clélia de Oliveira Lyra \\ Universidade Federal do Rio Grande do Norte \\ Natal, Rio Grande do Norte \\ E-mail: clelialyra@gmail.com}

\section{Cecile Soriano Rodrigues}

Universidade Federal de Pernambuco

Recife, Pernambuco

E-mail: cecilerodrigues@hotmail.com

Resumo: Objetivo: analisar as percepções de escolares sobre a construção de ambientes saudáveis na escola. Pesquisa-Ação em 4 escolas públicas de Ceilândia, DF. Foram realizadas 11 Oficinas em Dinâmica de Grupo, nelas os estudantes escreveram cartas aos educadores e gestores educacionais apontando mudanças para construírem um ambiente favorável à saúde. A análise de conteúdo das cartas desvelou aspectos estruturais que afetam o cotidiano. Resultados: postura crítica e propositiva dos estudantes na identificação de problemas e geração/avaliação de ideias. A participação produziu soluções realistas, factíveis e nem sempre evidenciadas sobre ambiência escolar, revelando novas possibilidade de intervenções em saúde que incentivem e possibilitem sua contribuição na transformação do ambiente onde vivem.

Palavras-chave: promoção da saúde, saúde escolar, inovação, participação social, pesquisa qualitativa.

\section{BUILDING HEALTHY ENVIRONMENTS IN SCHOOLS: INNOVATIONS IN CHILDREN'S PARTICIPATION}

Abstract: Aim: to analyze the schoolchildren perceptions about building healthy environments at school. Action research in four public schools in Ceilândia, DF. Eleven workshops were held in which the students wrote letters to educators and education managers pointing changes to build an environment conducive to health. The content analysis of the letters unveiled structural aspects that affect their everyday life. Results: students with critical and purposeful stance in identifying 
problems and generation/evaluation of ideas. Participation produced realistic, feasible and not always evidentiated solutions on school ambience both of them reveal new health intervention possibilities that encourage and enable schoolchildren contribution in transforming the environment in which they live.

Keywords: promotion health. school health. innovation. social participation. qualitative research.

Recebido em 28/11/2016. Publicado em 31/12/2016. 


\section{INTRODUÇÃO}

As ações para promover saúde se caracterizam por adotar uma estratégia mediadora entre pessoas e ambiente. São práticas que enfocam os determinantes sociais, articulam os saberes técnicos, populares e a participação de sujeitos. Tendo em vista melhorar a qualidade de vida e saúde, as iniciativas típicas de Promoção da Saúde (PS) incluem a formulação de políticas públicas saudáveis; o fortalecimento da participação social; a construção de ambientes saudáveis; o desenvolvimento de habilidades e a reorientação de serviços (Brasil, 2002).

Marca da PS, a participação ocorre quando "as intervenções consideram a visão de diferentes atores, grupos e coletivos na identificação de problemas e solução de necessidades como corresponsáveis no processo de planejamento, de execução e de avaliação das ações" (BRASIL, 2015). A Política Nacional de Promoção da Saúde (BRASIL, 2015) adota como princípio a participação social e a autonomia. Já a participação das crianças se refere ao processo no qual as crianças e os jovens se engajam com outras pessoas em torno de questões que afetam individual e coletivamente as suas condições de vida (HART, 2007).

Estes conceitos são ratificados no Plano Nacional de Educação (BRASIL, 2014a) ao recomendar a “(...) participação coletiva nas questões atinentes à organização e à gestão da educação incluindo (...) a constituição e o fortalecimento da participação estudantil (...)". O Programa Saúde na Escola corrobora a importância da "participação dos educandos (...) na construção e controle social das políticas públicas de saúde e educação" que corresponde a uma de suas diretrizes" (Brasil, 2007a, 2011).

Ao tratar da educação, o Estatuto da Criança e do Adolescente (ECA) institui a "participação ativa dos jovens no processo educativo em lugar de serem meros objetos passivos" (BRASIL, 2002) e assegura que, no plano local, "deverão ser criadas e reforçadas organizações juvenis que participem da gestão dos assuntos comunitários" (p. 171). Entretanto, poucas pesquisas abordam a participação de crianças no debate político ou em processos decisórios (Pérez, Póvoa, de Castro, e de Paula Monteiro, 2008). Sua ausência na tomada de decisão torna-se ainda mais inexplicável face às inúmeras questões relacionadas a elas, como educação, saúde, lazer e segurança (ALBUQUERQUE et al., 2014). 
Com frequência as crianças são vistas como seres destituídos de raciocínio ou desprovidos de sabedoria pela sua pouca experiência e por não poderem agir por si mesmas. A doutrina de proteção integral, consubstanciada no ECA (BRASIL, 2002) salienta mais "a sua fragilidade e dependência do que a intenção de criar condições para sua superação" (SIERRA e MESQUITA, 2006) e, por conseguinte, ao fornecer proteção e atender às suas necessidades, seu direito à participação é, frequentemente, desconsiderado.

O reconhecimento de que as crianças têm coisas importantes a dizer é um dos fatores que contribuem para melhorar o seu bem-estar (MANNION, 2007; TE ONE et al., 2014). Caso sejam ouvidas, isso as beneficiará e criará as condições de empoderamento, visto que a abordagem baseada no direito delas admite sua competência e capacidade. Tal perspectiva incentiva o exercício da cidadania potencial e salienta o lugar que que desse segmento ocupa na sociedade, situado entre sua condição atual e futura como cidadãs.

Em um estudo anterior realizado por Pérez et al. (2008), debateu-se a participação e ação em conjunto com crianças de 7 a 8 anos de idade pertencentes à classe média alta, moradoras do Rio de Janeiro. Ao final do estudo o jornal confeccionado por elas possibilitou a troca de sentimentos e de ideias sobre o bairro. Esta iniciativa ampliou sua percepção sobre a multiplicidade de usos, funções e interesses envolvidos na cidade. Outras pesquisas evidenciaram o interesse e a competência de estudantes ao tratar de questões que atingem a comunidade e a importância disso no planejamento e na implementação de programas (KALNINS et al., 2002; ALBUQUERQUE et al., 2014; TE ONE et al., 2014; ALBUQUERQUE et al., 2016a).

Segundo Sarmento (2002) o "processo político pedagógico de transformação social e institucional" requer dos educadores a ruptura "com o senso comum da acção educativa (...) que conduz à exclusão dos saberes das crianças". Esse esforço para "tornar a escola uma organização aprendente" demanda a "reconstituição e refundação cívica da escola" com base numa "lógica educativa pautada nos direitos das crianças". Requer ainda a compreensão de "como os saberes se tornam mais significativos, mais desejados e mais susceptíveis de provocar a felicidade dos alunos e promover sua cidadania activa".

Pautada numa perspectiva emancipatória, a inclusão de estudantes na construção de ambiente favorável à saúde contempla os componentes de iniciativas comunitárias exitosas: o 
reconhecimento das crianças como construtoras competentes na identificação de propostas e soluções para problemas existentes; a interação com adultos para favorecer o desenvolvimento de lideranças jovens e a geração de oportunidades para incluir jovens na tomada de decisão (FINN e CHECKOWAY, 1998; ALBUQUERQUE et al., 2014; WATERS e WHITE, 2015).

Cabe salientar que a efetiva implementação de ações orientadas pelos pressupostos da PS requer a transformação das práticas tradicionais e a inovação de novos modos de pensar, sentir e agir em saúde. Nessa perspectiva, Länsisalmi et al. (2006) ressaltam que a "inovação nos cuidados em saúde inclui novos serviços, novas formas de trabalhar e/ou novas tecnologias direcionadas a melhorar os resultados em saúde, eficiência administrativa, custo efetividade ou experiência dos usuários. Tudo isso implementado por uma ação planejada e coordenada". Na mesma direção Varkey et al., (2008) relacionam a inovação em saúde ao produto, ao processo ou à estrutura.

Nesse sentido a inovação no processo abrange mudanças no ato de produzir ou entregar um produto ou serviço que agrega valores para os interessados. Para isso é necessário: a identificação de problemas, a indicação e geração de ideias, a avaliação de ideias, o desenvolvimento, a primeira utilização, a comercialização e a difusão. Consistente com a inovação do processo, a PNPS (2015) salienta a importância de "estimular a pesquisa, a produção e a difusão de conhecimentos e de estratégias inovadoras no âmbito das ações de Promoção da Saúde".

Assim, o objetivo desse estudo é analisar a percepção de crianças acerca do processo de construção de ambientes saudáveis na escola.

\section{PERCURSO METODOLÓGICO}

A pesquisa fundamentou-se na abordagem qualitativa (MINAYO, 2009). Para isso empregou-se a Pesquisa-Ação, que se refere a "uma modalidade de intervenção coletiva, inspirada nas técnicas de tomada de decisão, que associa atores e pesquisadores em procedimentos conjuntos de ação com vista a melhorar uma situação precisa, avaliada com base em conhecimentos sistemáticos de seu estado inicial e apreciada com base em uma formulação compartilhada de objetivos de mudança" (DIONNE, 2007).

A perspectiva relacional desencadeada na Pesquisa-Ação tem um caráter de pesquisa formativoemancipatória com base na interação entre sujeitos por meio do diálogo que nasce do coletivo. 
Seu desenvolvimento se fundamenta numa ação comunicativa e interativa, a partir do mundo vivido, resultante da intersubjetividade gerada entre os sujeitos e manifestada como um saber teórico, prático ou expressivo (HABERMAS e DE ALMEIDA, 2003).

Centrado num cenário para ampliar a participação dos educandos e melhorar a atuação sobre o ambiente buscou-se o seu entendimento acerca do ambiente escolar. Isso foi gerado na troca de saberes e no processo dialógico desencadeado entre os sujeitos em Oficinas em Dinâmica de Grupo (ODG) (AFONSO, 2010). O entendimento originado nesse tipo de comunicação requer a validação dos seus participantes.

A inclusão das crianças nesse processo de interlocução e a escuta do seu entendimento sobre o espaço escolar encontra ressonância na questão epistêmica reconhecida por Delgado e Muller (2006): "como inscrever na pesquisa o ponto de vista e poder do outro? O outro não tem voz porque é negro, apátrida, pobre, analfabeto, estrangeiro, migrante, índio, criança (...)". Na sequência, os mesmos autores refletem sobre o método a ser adotado para atingir esse tipo de entendimento: “(...) a questão metodológica permite que a técnica de investigação seja um espaço democrático, participativo, dialógico, de construção de conhecimento, mesmo admitindo que o investigador adulto é quem tem o ultimo poder, o poder textual. Mas, esse pode (deve) ser não um poder que oprime ou oculta, mas um poder que clarifica e liberta" (DELGADO e MULLER, 2006).

Com base nesse pressuposto foram realizadas onze ODGs que consistem em "um trabalho estruturado com grupos, independente do número de encontros, focalizado em torno de uma questão central que o grupo se propõe a elaborar em um contexto social" (AFONSO, 2010). As ODGs vêm sendo apontadas na literatura científica como uma importante abordagem que favorece a criação de espaços críticos-reflexivos, valorizando-se os saberes prévios dos participantes e a construção coletiva de ações de mudanças na realidade operadas pelos próprios sujeitos.

O desenvolvimento de ODG ancora-se nos pressupostos da Psicologia de Grupos e da Pedagogia Libertadora (FREIRE, 2011). Sua implementação propicia um espaço que favorece a horizontalização e a articulação dos diferentes saberes. Fomenta a participação dos sujeitos e 
engatilha um processo reflexivo que valoriza não apenas a dimensão cognitiva, como também as dimensões afetivas e políticas a ele relacionadas.

O estudo foi realizado em quatro escolas públicas da Diretoria Regional de Educação (DRE) Ceilândia, Distrito Federal. A escolha se baseou em um diagnóstico realizado por Albuquerque (2011) por meio de amostra aleatória, que identificou 14,4\% de crianças de 6-12 anos com sobrepeso. Na sequência desenvolveram-se sete ODGs com duração média de 120 minutos, que aconteceram no período letivo, com a participação de 20 escolares por ODG totalizando 140 estudantes de 6-12 anos de idade. A partir de um planejamento previamente estabelecido, as ODGs incluíram atividades educativas, reflexivas e avaliativas. Tudo isso seguia uma sequência lógica para atingir os objetivos, favorecer a integração dos participantes, a construção do conhecimento e mudanças na realidade.

Seguindo as recomendações de Varkey et al., (2008) a geração de ideias adotada nesse estudo incluiu a busca na literatura, a observação participante do ambiente escolar e a realização de 'brainstorms' (ALBUQUERQUE et al., 2016a) efetuados previamente com estudantes e educadores das escolas pesquisadas como base para o planejamento das ODG. Com vistas a elucidar a variedade de perspectivas para o desenvolvimento de diversas soluções possíveis, os 'brainstorms' abrangem: a reunião de pessoas familiarizadas com o problema, a definição criteriosa do problema, a suspensão de julgamentos ou preconceitos, a criação de ambiente no qual os participantes sintam-se seguros para expressar suas ideias e encorajados a construir progressivamente sobre as ideias geradas (Varkey et al., 2008).

Cada ODG foi estruturada seguindo as etapas de acolhimento, integração, aquecimento para o tema, vivência, ampliação de informações, reflexão dialógica, aplicação e metacognição e avaliação. Para isso utilizaram-se recursos audiovisuais e técnicas lúdicas como músicas, brincadeiras infantis e vídeos que criassem um espaço favorável à interação, comunicação e reflexão sobre o tema abordado. Ao final de cada uma das ODG, propunha-se que cada estudante escrevesse uma carta para os educadores dizendo o que gostariam que mudasse na escola para terem um ambiente favorável à saúde. Esse espaço crítico e reflexivo criado com as ODGs contribuiu para os educandos apontarem sua perspectiva de ambiente facilitador de escolhas saudáveis. 
A seguir foram realizadas outras quatro ODG com a participação de pais e educadores (merendeiras, diretores, professores, professores de educação física), sendo uma em cada escola selecionada. Em cada um dos contextos, participaram cerca de quinze sujeitos, totalizando sessenta participantes. Durante estas ODG, os pais e educadores tiveram acesso às cartas redigidas pelos estudantes e também problematizaram os limites e possibilidades de construção de um ambiente escolar favorável à saúde.

Ao final, as cartas redigidas pelos estudantes constituíram o "corpus", sobre o qual se desenvolveu a análise de conteúdo guiada pelo plano de pesquisa e pelos objetivos do estudo. Nesse sentido, as frases extraídas dessas cartas, agrupadas por similaridade de temas, possibilitaram a identificação dos 'conteúdos manifestos', essas "unidades de significação que se libertam de um texto analisado segundo certos critérios relativos à teoria que serve de guia à leitura" (BARDIN, 2011). As categorias que se sobressaíram se referem à atividade física e à estrutura física do ambiente escolar.

A triangulação de métodos e de dados (FLICK, 2004) propiciou diferentes ângulos de visão e de compreensão da complexidade da realidade presente nas escolas. A coleta de dados se iniciou com a presença de observadoras participantes, que permaneceram por duas semanas, em dois turnos na mesma escola, em horários diferentes tais como início das aulas, na chegada das crianças, durante o recreio e no horário da merenda. A sequência de visitas foi guiada por um roteiro de observação que privilegiou as características físicas do contexto, os comportamentos e as interações pessoais. Em seguida realizaram-se quatro 'brainstorms', seguidos pelo planejamento e desenvolvimento de ODG (AFONSO, 2010). Ao final confrontaram-se os resultados das observações participantes, dos 'brainstorms' e das cartas escritas pelos escolares.

Os pais assinaram o termo de consentimento livre e esclarecido aprovado pelo Comitê de Ética em Pesquisa da Faculdade de Ciências da Saúde- Universidade de Brasília sob parecer no 092/10.

\section{RESULTADOS E DISCUSSÃO}

O reconhecimento das crianças como colaboradoras competentes para analisar o ambiente onde vivem seguiu o percurso da inovação do processo sugerido por Varkey et al., (2008) que propõe: a identificação de problemas existentes e a geração de ideias por meio da observação e dos 'brainstorms', a avaliação destas ideias, o desenvolvimento e primeira utilização nas escolas 
mediante a realização das ODGs, sua comercialização e difusão através das parcerias interinstitucionais e dos cursos de ODG ministrados para os profissionais da DRE-Ceilândia. Tudo isso acarretou a revelação de aspectos nem sempre evidenciados na percepção de estudantes das escolas públicas.

Um dos princípios constantes da PNPS é a autonomia "que se refere à identificação de potencialidades e ao desenvolvimento de capacidades, possibilitando escolhas conscientes de sujeitos e comunidades sobre suas ações e trajetórias" (BRASIL, 2015). Nesse sentido, um dos escolares aponta: Querida diretora, a escola 'tá em uma situação precária por isso estou escrevendo essa carta para que você pense no caso de melhorar a educação, a alimentação, os esportes e eu confio que a senhora vai deixar nossa escola muito bonita (ODG 1).

Os educandos identificam papéis, desvendam o poder existente na hierarquia interna da escola e colocam sua confiança na expectativa de que suas propostas sejam efetivadas. Isso evidencia sua "capacidade de formularem interpretações da sociedade, dos outros, de si próprias (...), dos pensamentos, dos sentimentos, de o fazerem de modo distinto e de o usarem para lidar com tudo o que as rodeia" (SARMENTO, 2006).

Essas propostas dos estudantes são condizentes com o Programa Mais Educação (PME) que atribui à direção da escola "o papel de incentivar a participação, o compartilhamento de decisões e de informações com professores, funcionários, estudantes e suas famílias" (BRASIL, 2007b). E, ao mesmo tempo, estão em consonância com a autonomia como categoria norteadora e conteúdo central da PS (FLEURY-TEIXEIRA et al., 2008).

O estudo de Sierra e Mesquita (2006) sugere medidas para contribuir na redução de vulnerabilidades deste grupo etário: “implementar gestão democrática em todas as instituições que atendem crianças e conceber a criança como ator social, incentivando sua participação na elaboração de políticas a elas direcionadas". Na pesquisa de Kalnins et al. (2002) a quase totalidade das crianças participantes encontrou meios de resolver os problemas colocados, evidenciando que não se sentiam destituídas de poder de decisão. Em algumas das situações propuseram estratégias nas quais elas, pessoalmente, resolviam os problemas. Em outras apontaram soluções estruturais para solucionar os problemas, mas não se viram agindo sozinhas. 
A condição descrita por Kalnins et al. (2002) e Davó-Blanes e La Parra (2013) se repete no presente estudo como representam a falas a seguir: "(...) melhorar o piso da escola, tampar os buracos o governo deveria melhorar o salário dos professores, auxiliares e funcionários, (...) melhorar os banheiros e bebedouros". (ODG 5). "Por favor, tente nos ajudar pedimos em nome da nossa escola. Obrigado" (ODG 7).

Ao concluir sua carta, o estudante destaca ainda a condição insatisfatória dos banheiros, ratificando a contribuição de Abramovay (2010), que aponta o espaço físico da escola como o aspecto que mais desagrada aos estudantes: “(...) ter mais limpeza nos banheiros, asfaltar o campo da quadra é só no barro, desentupir os bueiros (...) ter uma educação melhor (...) (ODG 6). É importante frisar que a PNPS (2015) considera a relevância de "promover e mobilizar (...) nos diferentes cenários como escolas (...) permitindo a interação entre saúde, meio ambiente e desenvolvimento sustentável e a produção social da saúde em articulação com os demais temas prioritários".

As condições precárias das escolas (ABRAMOVAY, 2010) saltam aos olhos de qualquer visitante que por elas circule, mas se depara com a insensibilidade do poder público para destinar recursos que propiciem um ambiente digno para a educação da juventude no país. As solicitações dos educandos para "melhorar na higiene e no ensino" e para 'ter uma educação melhor" (ODG 6) evidenciam uma percepção ampliada para aspectos da educação, que no fim das contas, é o objetivo precípuo da existência da escola.

Em consonância com o estudo de Davó-Blanes e La Parra (2013), as crianças indicam facetas do ambiente a serem melhoradas para prevenir acidentes e reduzir suas consequências. "Eu acho que tem que ter uma reforma na escola, melhorar o piso e o telhado (...) os bueiros fossem tampados, já vi uma criança se machucando neles, tinha que ter quadra de esportes, educação física, tinha que ter mais lixeiras (...) um exterminador de ratos. Esses tetos não estão seguros, qualquer hora pode cair o teto na cabeça de alguém" (ODG 1).

“Apoiar o desenvolvimento de espaços de produção social e ambientes saudáveis, favoráveis ao desenvolvimento humano e ao bem-viver" é um dos objetivos específicos da PNPS (2015). Consistente com este objetivo os escolares se reconhecem afetados pelo ambiente físico e social e pontuam aspectos estruturais fundamentais. Tal constatação exprime a multiplicidade de meios 
pelos quais o ambiente vem influenciando o cotidiano da escola. Levar em conta as solicitações dos educandos demanda mudança na sua organização política, na sua dinâmica de interação entre os diferentes segmentos ali existentes, bem como nas relações entre educadores e estudantes. Nesse sentido um dos participantes destaca um frase recorrente: "Os banheiros são muito fedorentos e pode arrumar" (ODG 2).

As soluções para os problemas não pertencem apenas a uma pessoa ou a um grupo, mas a toda comunidade presente no universo escolar. Por essa razão os diferentes segmentos que ali convivem deveriam se respeitar e negociar com base na paridade em busca de soluções comuns. Assim fazendo a educação contribui para reafirmar a identidade, encorajar a convergência de ideias e a construção conjunta de soluções que fortalecem a paz, a amizade e a solidariedade entre corpo docente e discente.

Outro problema destacado pelos escolares se refere aos diferentes tipos de violências ocorridas nas escolas: "Gostaria também que tivesse esporte na escola porque no recreio nós só corremos e 'se' batemos uns nos outros, machucamos" (ODG 2). Diferentes autores (FAKHRUDDIN et al., 2007; JOSSE, MACKAY, OSMOND e MACPHERSON, 2009; ALBUQUERQUE et al., 2016b) sugerem que os tipos de injúrias ocorridas na escola, tais como, distúrbios osteomusculares, fraturas e torções ocorridas na escola sucederam em jogos e na prática de atividade recreativa fora da sala de aula. Segundo Wyatt, Woodhams, Weinberg, Alao, e Mitchell (2010) a escola deveria eliminar jogos em ambiente que não ofereça segurança às crianças; separar ambientes onde se praticam jogos ou atividades recreativas mais agitadas daquelas mais calmas e fazer o manejo dos diferentes grupos etários para reduzir a ocorrência de acidentes.

Algumas soluções nesse sentido foram apontadas pelos estudantes que sugerem mudanças na organização do recreio para resguardar possíveis conflitos ou encontrões entre as crianças menores e maiores ao serem liberadas no mesmo horário: "O recreio está muito bagunçado, coloquem os menores em um horário, os maiores em outro" (ODG 2) ou "(...) que o recreio fosse separado para evitar acidentes". (ODG 5)

Uma das questões mais presentes nas cartas dos educandos com vistas à construção de um ambiente saudável se refere à necessidade de ambiente adequado para desenvolverem atividade física como evidenciam os fragmentos expressivos a seguir: "mais esporte, reformassem a quadra 
para a gente fazer exercícios e outros esportes" (ODG 5). "queria (...) aulas de educação física, ia ser divertido e ia fazer bem à saúde” (ODG 1).

A incorporação da "atividade física como fator determinante e condicionante de saúde" ocasionou mudança recente na legislação (BRASIL, 2013) por meio da alteração do caput da Lei 8.080 (1990). Ademais um dos macrocampos do PNE denominado Promoção da Saúde inclui as atividades físicas e corporais (BRASIL, 2014b). As principais barreiras para implementar educação física na escola foram identificadas na literatura por Young et al. (2007) a educação física não constitui prioridade para a escola nem para os estudantes; a insuficiência de recursos financeiros para manutenção de quadras e de equipamentos; o despreparo de profissionais. Ao mesmo tempo o estudo de Damazio e Silva (2008) e Albuquerque et al., (2016c) destacam a falta de recursos para quadras e equipamentos adequados; a falta de oportunidade de fazer atividade física; a dispensa injustificada de estudantes e o cancelamento de atividades escolares. Isso sinaliza para o estudante a pouca valorização que a escola atribui à educação física.

Ao apontar fatos e expressar seu ponto de vista com clareza de detalhes, os educandos têm uma postura crítica, propositiva na identificação dos problemas e naquilo que gostariam de modificar, como pode ser visto na fala a seguir: "Eu gostaria que reformasse as cadeiras (...) era muito bom se tivesse quadras (...) educação física (...) era muito bom" (ODG 5). Ao repetir 'era muito bom' desvelam o sonho de um futuro melhor com base na ambiência desfavorável com que se defrontam no cotidiano escolar.

Nas frases recorrentes relacionadas à abertura da quadra, à liberação da bola, das cordas, às festas e ao preço dos passeios as crianças reportam também a necessidade de maximizar oportunidades de lazer. Sua compreensão de lazer corresponde às atividades sociais que propiciam "relacionamentos interpessoais" (BACHELADENSKI e MATIELLO JÚNIOR, 2010): “ mais brincadeira (...) fazer mais amigos" (ODG 2) "(...) queria que minha turma fosse para a quadra, faz seis meses que a gente não vai para a quadra", (ODG 3) "(...) colocassem bolas, cordas, elástico e brinquedos" (ODG 1) "deixassem a quadra aberta para nós podermos brincar", (ODG 2) "(...) colocar música nos intervalos", (ODG 7) "(...) ter mais festa na escola e baixar o preço dos passeios" (ODG 7) 
Por outro lado, apesar de se sentirem no direito de apresentar exigências e propostas de mudanças para a escola, também foi possível perceber a insegurança dos estudantes no que tange à consideração das suas sugestões pelos gestores escolares. Nesse sentido, uma das crianças afirma: "Eu sei que não vai ajudar em nada, mas eu queria muito que nas salas tivessem um bebedouro de água e um banheiro, tem vezes que os professores não 'deixa' a gente ir ao banheiro e tem pessoas que fazem xixi nas calças. Por isso que eu estou pedindo para prevenir. Eu queria também que os banheiros fossem mais limpos. Obrigada" (ODG 5).

O descrédito manifestado por este escolar quanto ao efeito da opinião dele, deriva da sua vivência, na qual se verifica exclusão do segmento estudantil do processo de tomada de decisão. Sua solicitação é legítima e relativamente simples de ser atendida, mas o depoimento expressa descrença no cumprimento de sua pretensão. Esse depoimento corrobora outra pesquisa que conclui pela escassez de experiência dos educadores para escutar as crianças no repertório de práticas coletivas escolares (Castro, 2001; ALBUQUERQUE et al., 2016b).

Isso reitera a ideia que "as relações de poder que se estabelecem nos ambientes escolares poderão servir de ambiente para a promoção da participação infantil” (PIRES e BRANCO, 2007). Apesar das cartas trazerem propostas realistas, relevantes e consistentes, os estudantes não se veem, eles mesmos, resolvendo os problemas apontados. Teriam eles assimilado o conjunto de prescrições e de interdições, de formas de entendimento e modos de actuação, que se inscrevem na definição do que é admissível e do que é inadmissível fazer para as crianças ou que as crianças façam? (DELGADO e MULLER, 2006; SARMENTO, 2006).

Assim, as crianças, como sujeitos do devir, têm seus direitos subtraídos pelos adultos, têm reduzidas suas possibilidades de inserção na sociedade que toma o seu lugar e, em lugar de construir com elas, constrói para elas. Entretanto, a visão abrangente consubstanciada nas frases dos estudantes contradiz esse olhar reducionista dos adultos. O conteúdo das cartas contempla a opinião de Deleuze, em sua conversa com Foucalt (2014): "Se as crianças conseguissem que seus protestos, ou simplesmente suas questões, fossem ouvidos em uma escola maternal, isso seria o bastante para explodir o sistema de ensino".

Entretanto, as instituições sociais como escolas, têm um longo caminho a percorrer para se transformarem em ambientes de convívio que privilegiem a interação pessoal, criativa e 
autônoma. Para se articularem a demandas sociais de maneira eficaz e para direcionarem sua atuação numa perspectiva de formação de consciência crítica e de ampliação da liberdade.

No processo de inovação a comercialização constitui um dos elementos do percurso de Varkey et al., (2008). Isso pode se realizar sob duas formas básicas, além daquela tradicional que faz uso da moeda em seu papel como meio de troca: numa delas, pelo escambo, denominação utilizada para designar a prática da troca de serviço ou mercadoria sem fazer uso da moeda. Em outra, o pagamento pela produção do serviço ou mercadoria é feito indiretamente, ou seja, um terceiro assume parcialmente as despesas com a cessão de recursos humanos e/ou materiais. Nesta forma, puderam colaborar não só um terceiro, mas outros que consubstanciaram uma parceria interinstitucional, potencializaram os recursos humanos e materiais, criando oportunidade de articular saberes.

Outra modalidade de cooperação ou parceria se configurou na intensidade de esforço para superação das dificuldades encontradas ao longo desse estudo e se referiu ao tipo de projeto, que tinha muitas frentes de trabalho. Isso exigiu diligência e dedicação para compatibilizar o tempo da pesquisa com o conjunto das atribuições docentes. Essa disponibilidade encontrou reciprocidade no empenho e sensibilidade das diretoras para conciliar o cronograma apertado das escolas com a agenda do estudo epidemiológico, dos 'brainstorms' e das oficinas.

$\mathrm{Na}$ etapa subsequente, aqui entendida como difusão, os resultados da pesquisa foram apresentados à equipe da DRE Ceilândia (nutricionistas, auxiliares de merenda, diretores das escolas e diretor da DRE). Seu propósito era contribuir na construção de um ambiente escolar que favoreça escolhas saudáveis e seja facilitador de práticas esportivas e de atividade física. Mesmo depois da conclusão desta pesquisa foram oferecidos mais dois cursos para o desenvolvimento de ODGs dirigido às nutricionistas da DRE Ceilândia e a outras nutricionistas vinculadas à Secretaria de Estado de Educação. Até mesmo a publicação configura uma maneira de difusão.

\section{CONSIDERAÇÕES FINAIS}

A participação favoreceu a apropriação do ambiente escolar, criou oportunidade para os escolares refletirem sobre os problemas do espaço onde estudam e os envolveu na contribuição ao processo de tomada de decisões. O emprego das ODGs desencadeou um tipo de abordagem que privilegiou a estratégia de baixo para cima (bottom-up) e priorizou o ponto de vista dos estudantes 
em lugar da perspectiva dos educadores. Sua utilização atendeu à expectativa de construção coletiva, de resgate dos saberes, de ampliação do espaço de participação e de interação, próprios das iniciativas para promover saúde.

As sugestões contidas nas cartas dos estudantes para que a comunidade escolar possa desfrutar de um ambiente mais saudável e facilitador de escolhas salutares trazem referências para refletir sobre questões mais amplas. As ideias apresentadas são realistas, aplicáveis, factíveis e passíveis de ser objeto de ocupação dos tomadores de decisão em diferentes níveis: locais, estaduais e federais. Por conseguinte, sugerem a adoção de um desenho inovador nas intervenções desenvolvidas visto que apontam para inclusão das sugestões dos educandos na organização do ambiente escolar.

Os estudantes apresentaram competência para a participação social, uma vez que encontraram espaço adequado e ouvido atento às suas diferentes formas de expressão. Os resultados deste estudo salientam a necessidade da interface da escola com os direitos da criança em todas as dimensões, que estão registrados no arcabouço legal vigente. Ao mesmo tempo, geram a oportunidade de ir além do seu potencial e ver do que são capazes hoje. Isso está em consonância com a concepção que considera os jovens o presente do país e não apenas o seu futuro.

A inclusão dos educandos como parceiros na construção de ambiente favorável à saúde evidencia sua competência para analisar criticamente o meio onde vivem e para representarem a si mesmas com uma contribuição relevante, construtiva e criativa ao debate. Propicia o resgate da autonomia e a reposição destes sujeitos na centralidade dos processos decisórios e de transformação por meio da legitimação de sua voz e de suas perspectivas. Tal atitude questiona as práticas tuteladoras existentes nas escolas e aponta na direção de novas formas de organização e representação deste segmento etário. Parece ser o momento de rever a posição e o papel atribuído à criança para não perder seu potencial valioso e seu engajamento nas mudanças a serem implementadas no âmbito escolar.

A ruptura com as relações assimétricas de poder que, muitas vezes, caracterizam o ambiente escolar propicia a formação destes estudantes como sujeitos sociais ativos. Ao mesmo tempo requer a apreensão de diferentes modos para lidar com os estudantes de forma emancipatória, dado que a escola atinge essa população juvenil em fase de formação. Isso implica deslocar as 
iniciativas a serem implementadas da perspectiva dos adultos na direção da perspectiva das crianças, encaradas como parceiras na identificação de necessidades, na construção de propostas e de soluções. Implica também no reconhecimento da capacidade e do potencial que os educandos demonstraram por meio de uma postura propositiva.

Essa pesquisa enfatizou o resgate da percepção dos educandos em relação à atividade física para, em seguida, identificar as mudanças necessárias ao ambiente físico escolar como suporte para escolhas mais saudáveis. Assim fazendo reconhece o valor desses participantes na construção da identidade pessoal, social e dos ambientes onde vive. As informações coletadas no processo de observação participante e nos 'brainstorms' proporcionaram uma variedade de informações que confirmaram o conteúdo das cartas escritas pelos estudantes durante as ODGs.

\section{AGRADECIMENTOS}

Agradecimentos ao CNPq por ter financiado esta pesquisa, bem como ao corpo docente e discente das Escolas e à Diretoria Regional de Educação-Ceilândia.

\section{REFERÊNCIAS}

ABRAMOVAY, M. (2010). O bê-a-bá da intolerância e da discriminação. Brasília: Unicef.

AFONSO, M. L. M. (2010). Oficinas Em Dinamica de Grupo: Um Metodo de: Casa do Psicólogo.

ALBUQUERQUE, OMR. (2011). Relatório do projeto "Revisão sistemática sobre o efeito de intervenções educativas dirigidas a escolares para redução da obesidade infantil como subsídio para intervenção em escolas da Regional de Ensino-Ceilândia, DF": Brasília, DF: CNPq.

SILVESTRE, CC., ALMEIDA, JV., CONCEIÇÃO MH., ALBUQUERQUE, OMR., (2016). Análise de promoção das práticas corporais e atividade física propostas pelo Programa Saúde na Escola nas escolas de Samambaia/Distrito Federal CIAIQ2016, 2(0).

ALBUQUERQUE, OMR., CAMPOS, H., ALVES, C., MARTINS, AM. (2016). A participação de crianças na construção de ambientes saudáveis na escola é uma fantasia ou um sonho possível? CIAIQ2016, 2(0).

ALBUQUERQUE, OMR., CAMPOS, H., ALVES, C., MARTINS, AM. (2016). Estudantes e educadores de escolas públicas: o que eles pensam sobre alimentação? CIAIQ2016, 2(0).

Albuquerque, OMR., MARTINS, AM., MODENA, C., E CAMPOS, H. Percepção de estudantes de escolas públicas sobre o ambiente e a alimentação disponível na escola: uma abordagem emancipatória. Saúde e Sociedade, v. $23, \mathrm{n}$. 2, 604-615, 2014. doi:10.1590/s0104-12902014000200020

BACHELADENSKI, M. S., MATIELLO JÚNIOR, E. Contribuições do campo crítico do lazer para a promoção da saúde. Cien Saude Colet, v. 15n. 5, p. 2569-2579, 2010. 
BARDIN, L. Análise de conteúdo. 3. reimp. Lisboa: Ediçoes, 70, 2011.

BRASIL. (2002). Estatuto da Criança e do Adolescente. Normativas Internacionais. Convenções № 138 e 182 , Recomendação № 190 - OIT. Portaria no. 6/2002. Brasília: Ministério da Justiça.

BRASIL. (2007a). Decreto 6.286 de 05 de dezembro de 2007. Institui o Programa Saúde na Escola e dá outras providências. Programa Saúde na Escola. 2007. Brasília: Ministério da Educação e da Saúde Retrieved from http://www.planalto.gov.br/ccivil_03/_Ato2007-2010/2007/Decreto/D6286.htm.

BRASIL. (2007b). Portaria Normativa Interministerial no 17, de 24 de abril de 2007. Institui o Programa Mais Educação, que visa fomentar a educação integral de crianças, adolescentes e jovens, por meio do apoio a atividades sócioeducativas no contraturno escolar. . Brasília: Diário Oficial da União.

BRASIL (2011). Instrutivo Programa Saúde na Escola. Brasília: Ministério da Saúde.

BRASIL (2013). Lei n. 12.864 de 24 de setembro de 2013. Altera o caput do art. 13 da lei 8.080 de 19 de setembro de 1990 incluindo a atividade física como fator determinante e condicionante de saúde. Brasilia: Diário Oficial da União.

BRASIL (2014a). Plano Nacional da Educação. Brasília: Ministério da Educação.

BRASIL (2014b). Portaria № 2.446, de 11 DE novembro de 2014. Redefine a Política Nacional de Promoção da Saúde (PNPS). Brasilia.

BRASIL (2015). Política Nacional de Promoção da Saúde Revisão da Portaria no. 687, de 30 de março de 2006. Brasília: Ministério da Saúde.

CASTRO, L. R. Subjetividade e cidadania: um estudo com crianças e jovens em três cidades brasileiras. Rio de Janeiro: 7Letras, 2001.

DAMAZIO, M. S., SILVA, M. F. P. O ensino da educação física e o espaço físico em questão. Pensar a prática, v. 11, n. 2, p.189-196, 2008.

DAVÓ-BLANES, M. C., LA PARRA, D. Children as agents of their own health: exploratory analysis of child discourse in Spain. Health promotion international, v. 28n. 3, p. 367-377, 2013.

DELGADO, A. C. C., MULLER, F. Infâncias, tempos e espaços: um diálogo com Manuel Jacinto Sarmento. Currículo sem fronteiras, v. 6 n. 1, p. 15-24, 2006.

DIONNE, H. A pesquisa: ação para o desenvolvimento local Pesquisa (Vol. 16): Braília: Liber Livro, 2007.

FAKHRUDDIN, K. S., LAWRENCE, H. P., KENNY, D. J., LOCKER, D. Etiology and environment of dental injuries in 12-to 14-year-old Ontario schoolchildren. Dental traumatology, v. 24, n. 3, p. 305-308, 2007.

FINN, J. L., CHECKOWAY, B. Young people as competent community builders: A challenge to social work. Social work, v. 43n. 4, p. 335-345, 1998.

FleURY-TEIXEIRA, P., VAZ, F. A. C., CAMPOS, F. D., ÁlVARES, J., AGUIAR, R. A. T., OliVEIRA, V. d. A. Autonomia como categoria central no conceito de promoção de saúde. Ciênc Saúde Coletiva, v. 13(Supl 2), p. 2115-2122, 2008.

FLIK, U. Triangulation in Qualitative Research. A Companion to Qualitative Research, London : Sage, 2005. p. 432. doi:10.1016/S0261-5177(98)00102-2

FOUCALT, M. Microfísica do poder. Rio de Janeiro: Graal, 2014.

FREIRE, P. Pedagogia do oprimido. Rio de Janeiro: Editora Paz e Terra, 2011. 
HABERMAS, J., e de Almeida, G. A. Consciência moral e agir comunicativo. Rio de Janeiro: Tempo brasileiro, 2003.

HART, J. Empowerment or Frustration? Participatory programming with young Palestinians. Children Youth and Environments, v. 17n. 3, p. 1-23, 2007.

JOSSE, J. M., MACKAY, M., OSMOND, M. H., MACPHERSON, A. K. School Injury Among Ottawa-Area Children: A Population-Based Study. Journal of school health, v. 79 n. 2, p. 45-50, 2009.

KALNINS, I., HART, C., BALLANTYNE, P., QUARTARO, G., LOVE, R., STURIS, G., POLLACK, P. Children's perceptions of strategies for resolving community health problems. Health promotion international, v. 17, n. 3, p. 223-233, 2002.

LÄNSISALMI, H., KIVIMÄKI, M., AALTO, P., RUORANEN, R. Innovation in healthcare: a systematic review of recent research. Nursing science quarterly, v. 19n. 1, p. 66-72, 2006; discussion 65. doi:10.1177/0894318405284129

MANNION, G. Going spatial, going relational: Why "listening to children" and children's participation needs reframing. Discourse: studies in the cultural politics of education, v. 28 n. 3, p. 405-420, 2007.

MINAYO, M. C. d. S. Pesquisa social: teoria, método e criatividade. Rio de Janeiro: Vozes, 2009.

PÉREZ, B. C., PÓVOA, J. M., DE CASTRO, L. R., DE PAULA MONTEIRO, R. A. Cidadania e participação social: um estudo com crianças no Rio de Janeiro. Revista Psicologia \& Sociedade, v. 20, n. 2, p. 181-191, 2008.

PIRES, S. F. S., BRANCO, A. U. Protagonismo infantil: co-construindo significados em meio às práticas sociais. V. 17, n. 38, p. 311-320, 2007.

SARMENTO, M. J. Infância, exclusão social e educação como utopia realizável. Educação \& Sociedade, v. 23, n. 78, p. 265-283, 2002.

SARMENTO, M. J. (2006). Gerações e alteridade: interrogações a partir da sociologia da infância. Educação e Sociedade. V.26, n.91, p. 361-378, 2005.

SIERRA, V. M., MESQUITA, W. A. Vulnerabilidades e fatores de risco na vida de crianças e adolescentes. São Paulo em Perspectiva, v. 20n. 1, p. 148-155, 2006.

TE ONE, S., BLAIKIE, R., EgAN-BITRAN, M., HENLEY, Z. You Can Ask Me If You Really Want to Know What I Think. Educational Philosophy and Theory, v. 46n. 9, p. 1052-1068, 2014.

VARKEY, P., HORNE, A., BENNET, K. E. Innovation in health care: a primer. American journal of medical quality : the official journal of the American College of Medical Quality, v. 23, n. 5, p. $382-388.2008$ doi:10.1177/1062860608317695

WATERS, L., WHITE, M. Case study of a school wellbeing initiative: Using appreciative inquiry to support positive change. International Journal of Wellbeing, v. 5 n.1, p. , 2015.

WYATT, J. P., WOODHAMS, S., WEINBERG, L., ALAO, D., MITCHELL, L.. A prospective study of injuries inflicted on children by children. Journal of forensic and legal medicine, v. 17 n. 1, p. 8-10, 2010.

YOUNG, D. R., FELTON, G. M., GRIESER, M., ELDER, J. P., JOHNSON, C., LEE, J. S., KUBIK, M. Y. Policies and opportunities for physical activity in middle school environments. Journal of school health, v. 77, n. 1, p. 41-47, 2007. 